\title{
Retraction
}

\section{Retracted: Design of a Narrow Bandwidth Bandpass Filter Using Compact Spiral Resonator with Chirality}

\author{
Active and Passive Electronic Components \\ Received 12 May 2019; Accepted 12 May 2019; Published 9 June 2019 \\ Copyright (C) 2019 Active and Passive Electronic Components. This is an open access article distributed under the Creative \\ Commons Attribution License, which permits unrestricted use, distribution, and reproduction in any medium, provided the \\ original work is properly cited.
}

Active and Passive Electronic Components has retracted the article titled "Design of a Narrow Bandwidth Bandpass Filter Using Compact Spiral Resonator with Chirality" [1]. The article took the figures, the table, and most of the text from an unpublished article by Drs. Mohammad Reza Khawary, Seyed Mohammad Hashemi, Vahid Nayyeri, and Mohammad Soleimani previously submitted to IEEE Microwave and Wireless Components Letters in August 2015. The other journal confirmed the details of that earlier submission.

The first author does not agree with retraction and says their laboratory conducted this work, which was done by a former, unnamed student, and any similarity is a coincidence. We could not contact the other authors. The first author provided what they said were original simulation and measurement results, and said different software was used during filter design, simulation, optimization, and fabrication: CST for EM simulation, HFSS for resonant frequency extraction, ADS for circuit simulation, and AutoCAD for drawing the layout for fabrication; the filter was measured using R\&S vector network analyzer.

\section{References}

[1] W. Li, Z. Tang, and X. Cao, "Design of a narrow bandwidth bandpass filter using compact spiral resonator with chirality," Active and Passive Electronic Components, vol. 2016, Article ID 7074392, 6 pages, 2016. 